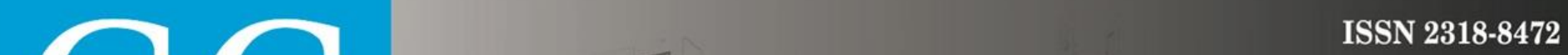

Revista Nacional de

\title{
Avaliação do Comportamento Mecânico de Concreto Não Estrutural Produzido com Resíduos de Construção Civil
}

\author{
Evaluation of the Mechanical Behavior of Non-Structural Concrete Produced with Civil \\ Construction Waste
}

Evaluación del Comportamiento Mecánico de Hormigón No Estructural Producido con Residuos de Construcción Civil

Leticia Martelo Pagoto

Aluna de Mestrado, UNESP Ilha Solteira, Brasil. leppagoto@yahoo.com.br

Simone Cristina Caldato da Silva Professora Mestre, UNILINS, Brasil. simonecaldato@hotmail.com 


\section{RESUMO}

A preocupação com o descarte inadequado de resíduos de construção civil vem se tornando cada vez maior nos dias atuais devido aos impactos ambientais causados. Uma possível solução para este problema é inseri-los na produção de concreto com substituição dos agregados convencionais pelos oriundos do processo de reciclagem dos resíduos de construção civil, afim de atingir uma resistência considerável, não estrutural, e aplicá-lo em artefatos de concreto, como proposto neste trabalho. Para este estudo, os materiais reciclados foram cedidos pela Usina de Reciclagem de Resíduos da Construção Civil, Eco Solutions, e os agregados convencionais foram provenientes da região de Lins, havendo comparação entre o concreto com os materiais reciclados e o concreto convencional. Os materiais passaram por ensaios de caracterização e dosagens, foram moldados corpos de prova com os traços determinados, para ensaios de resistência à compressão e tração por compressão diametral, segundo as normas vigentes da Associação Brasileira de Normas Técnicas. O concreto com os materiais reciclados atingiu uma resistência razoável, mesmo com alguns pontos desfavoráveis nos ensaios de caracterização, e pode ser aplicado em artefatos de concreto, como por exemplo em bancos, grelhas e pingadeira de muro.

PALAVRAS-CHAVE: Concreto não estrutural. Resíduos de construção civil. Resistência mecânica.

\section{ABSTRACT}

Concern about the inadequate disposal of civil construction waste is becoming more and more important today due to the environmental impacts caused. A possible solution to this problem is to insert them in the production of concrete with substitution of the conventional aggregates by those coming from the process of recycling of the civil construction waste, in order to achieve a considerable non-structural resistance and to apply it in concrete artifacts, as proposed in this work. For this study, the recycled materials were provided by the Civil Construction Waste Recycling Plant, Eco Solutions, and the conventional aggregates came from the Lins region, with a comparison between the concrete with the recycled materials and the conventional concrete. The materials underwent characterization tests and dosages, molded test specimens with the determined traits for tests of compressive strength and diametral compression traction, in accordance with the norms in force of the Brazilian Association of Technical Norms. Concrete with recycled materials has reached a reasonable resistance, even with some unfavorable points in the characterization tests, and can be applied to concrete artifacts, benches, grates and wall dripping.

KEY WORDS: Non-structural concrete. Civil Construction Waste. Mechanical resistance.

\section{RESUMEN}

La preocupación por el descarte inadecuado de residuos de construcción civil se está volviendo cada vez mayor en los días actuales debido a los impactos ambientales causados. Una posible solución para este problema es insertarlos en la producción de hormigón con sustitución de los agregados convencionales por los oriundos del proceso de reciclado de los residuos de construcción civil, a fin de alcanzar una resistencia considerable, no estructural, y aplicarlo en artefactos de hormigón, como se propone en este trabajo. Para este estudio, los materiales reciclados fueron cedidos por la Usina de Reciclaje de Residuos de la Construcción Civil, Eco Solutions, y los agregados convencionales provenían de la región de Lins, habiendo comparación entre lo hormigón con los materiales reciclados y el hormigón convencional. Los materiales pasaron por ensayos de caracterización y dosificación, fueron moldeados cuerpos de prueba, con los trazos determinados, para ensayos de resistencia a la compresión y tracción por compresión diametral, según las normas vigentes de la Asociación Brasileña de Normas Técnicas. El hormigón con los materiales reciclados alcanzó una resistencia razonable, incluso con algunos puntos desfavorables en los ensayos de caracterización, y puede ser aplicado en artefactos de hormigón, como por ejemplo en piezas de pavimentación, bancos, rejillas y cajón de muro.

PALABRAS CLAVE: Hormigón no estructural. Residuos de construcción civil. Resistencia mecánica. 


\section{INTRODUÇÃO}

O crescimento acelerado das cidades, o desenvolvimento tecnológico, o aumento populacional e a intensa industrialização desencadearam uma série de transformações no espaço geográfico e entre elas se destaca a construção civil.

Um dos impactos provenientes da indústria da construção civil é a utilização dos recursos naturais finitos como matéria prima e outro é a geração de resíduos descartados de forma inadequada, os quais provocam problemas de ordem ambiental, estética e de saúde pública.

Segundo a Associação Brasileira para Reciclagem de Resíduos da Construção Civil e Demolição - ABRECON (2018), o primeiro registro significativo da utilização de resíduo de construção foi após a Segunda Guerra Mundial, onde foram reconstruídas as cidades da Europa. Os escombros da demolição foram britados, buscando a produção de agregado para atingir a demanda da época. Portanto, foi a partir de 1946 que teve início o desenvolvimento da tecnologia de reciclagem de resíduo da construção civil.

Os resíduos gerados em obras podem ser latas de tinta, sobras de argamassa, concreto, gesso, sacos plásticos ou de papelão, materiais cerâmicos, solos de terraplenagem, entre outros. Esses materiais podem ser classificados em quatro classes distintas, segundo o Conselho Nacional do Meio Ambiente - CONAMA em sua resolução $n^{\circ} 307$ (BRASIL, 2002). Na Classe A, estão aqueles que podem ser reutilizados na mesma obra; os de Classe $B$ podem ser reciclados para outros usos; Classe $C$ não podem ser reciclados ou reutilizados; e Classe $D$ são resíduos considerados perigosos ao meio ambiente e à saúde humana.

O concreto reciclado utiliza esses resíduos de construção civil - RCC em substituição total ou parcial do agregado graúdo e miúdo para sua obtenção. Neste trabalho, foram utilizados resíduos da Usina de Reciclagem de Resíduos da Construção Civil, Eco Solutions, em Lins - SP para produzir o concreto reciclado, e sua execução foi no Laboratório de Ensaios de Materiais - LEM da Unilins, em Lins - SP.

\section{OBJETIVO}

O presente trabalho tem como objetivo estudar o comportamento mecânico do concreto não estrutural produzido com substituição total dos agregados convencionais por RCC por meio de ensaios de consistência, resistência à compressão e resistência à tração por compressão diametral e propor possíveis aplicações em artefatos de concreto. 


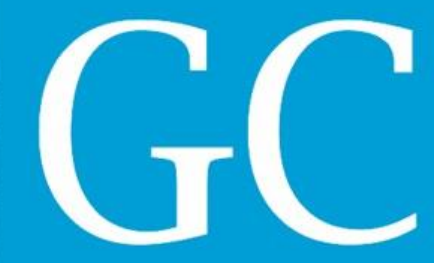

ISSN 2318-8472

Revista Nacional de

\section{METODOLOGIA}

\subsection{MATERIAIS}

Para a confecção dos traços de concreto em estudo foram utilizados cimento Portland CPII E 32 Votoran, agregado graúdo (brita 1) e miúdo (areia grossa) de origem natural (Figura 1) e os materiais recicláveis denominados brita reciclada e areia reciclada (Figura 2).

Os materiais reciclados, brita e areia reciclada, foram fornecidos pela Usina de Reciclagem de Resíduos da Construção Civil, Eco Solutions (Lins, SP), que recebe os RCC de obras localizadas na região de Lins e os recicla por meio do processo de britagem em britadores de martelos, transformando-os nos agregados comercializados pela empresa.

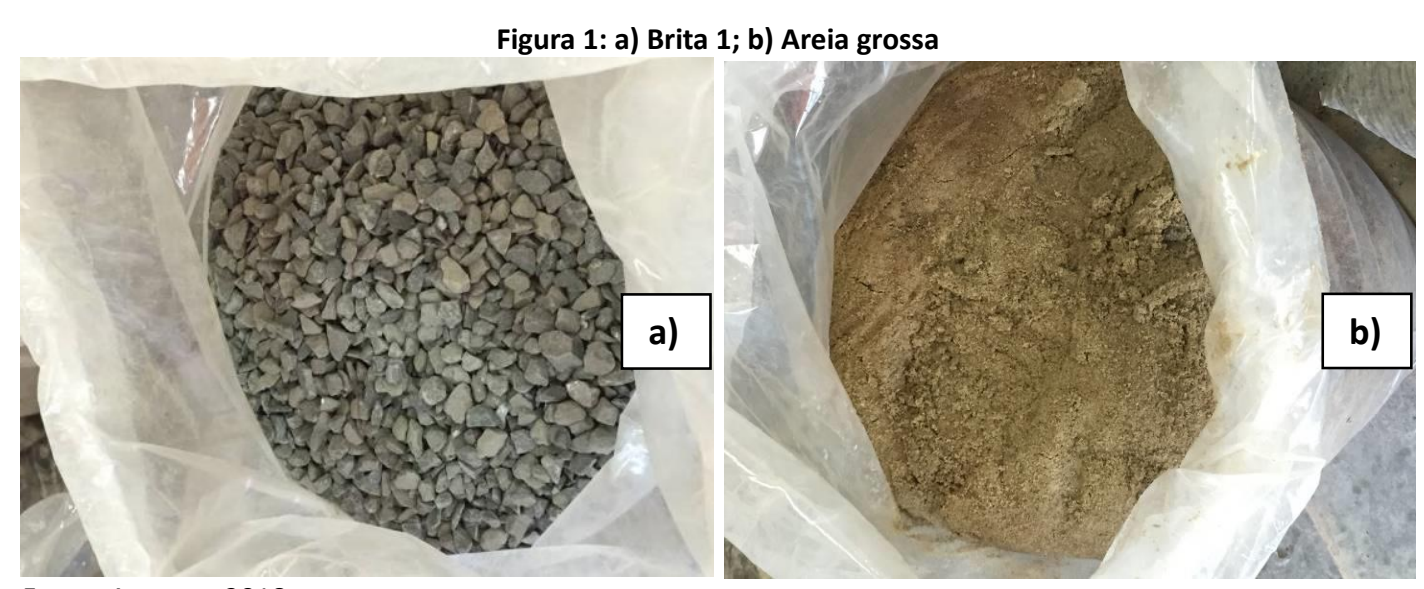

Fonte: Autores, 2018.

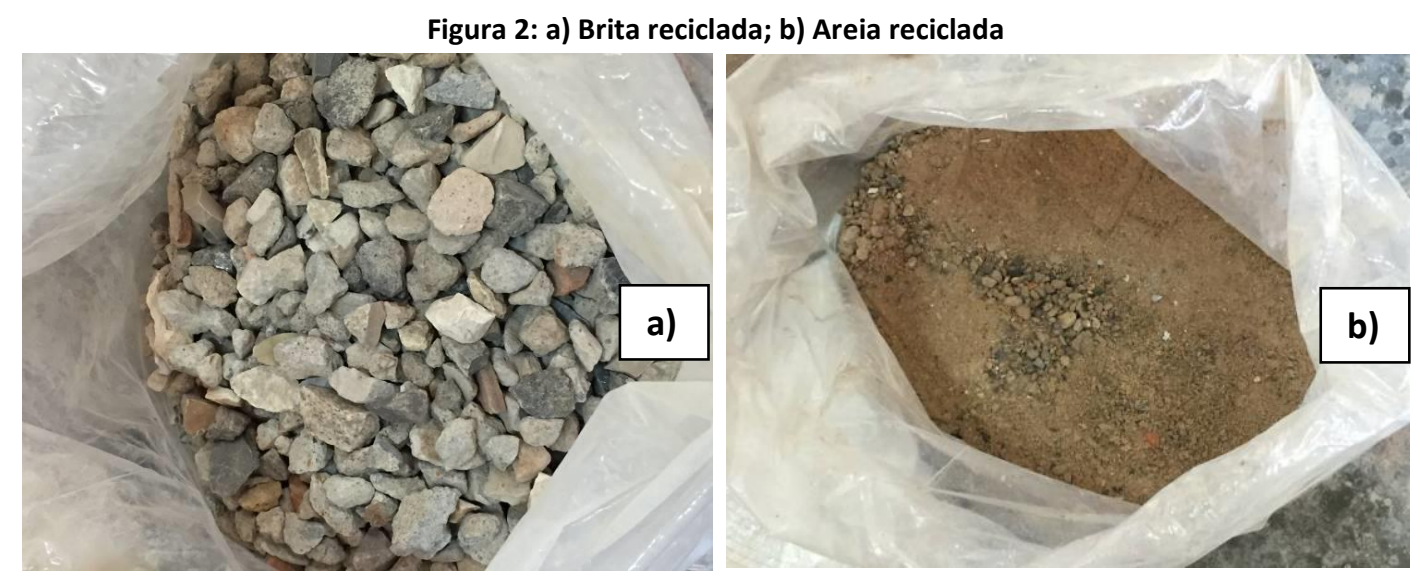

Fonte: Autores, 2018.

Foram realizados ensaios de caracterização para os materiais utilizados seguindo as normas vigentes da Associação Brasileira de Normas Técnicas - ABNT, apresentadas no Quadro 1 e os resultados dos ensaios estão apresentados na Tabela 1. 


\section{Revista Nacional de}

Quadro 1: Normas utilizadas nos ensaios de caracterização dos materiais

\begin{tabular}{|l|c|c|c|}
\hline \multicolumn{1}{|c|}{ Ensaios } & Cimento & Brita 1 e brita reciclada & $\begin{array}{c}\text { Areia grossa e areia } \\
\text { reciclada }\end{array}$ \\
\hline Massa específica absoluta & NBR 16605 (ABNT, 2017) & NBR NM 53 (ABNT, 2009) & NBR NM 52 (ABNT, 2009) \\
\hline Massa específica aparente & - & NBR NM 53 (ABNT, 2009) & NBR NM 52 (ABNT, 2009) \\
\hline Módulo de finura & - & NBR NM 248 (ABNT, 2003) & NBR NM 248 (ABNT, 2003) \\
\hline Dimensão máxima característica & - & NBR NM 248 (ABNT, 2003) & NBR NM 248 (ABNT, 2003) \\
\hline Absorção de água & - & NBR NM 53 (ABNT, 2009) & - \\
\hline Volume de vazios & - & NBR NM 45 (ABNT, 2006) & NBR NM 45 (ABNT, 2006) \\
\hline Massa unitária & - & NBR NM 45 (ABNT, 2006) & NBR NM 45 (ABNT, 2006) \\
\hline Pulverulento & - & NBR NM 46 (ABNT, 2003) & NBR NM 46 (ABNT, 2003) \\
\hline
\end{tabular}

Fonte: Autores, 2018.

Tabela 1: Resultados dos ensaios de caracterização dos materiais

\begin{tabular}{lccccccccc}
\hline Materiais & $\begin{array}{c}\text { Massa } \\
\text { específica } \\
\text { absoluta } \\
\left(\mathbf{g} / \mathbf{c m}^{\mathbf{3}}\right)\end{array}$ & $\begin{array}{c}\text { Massa } \\
\text { específica } \\
\text { aparente } \\
\left(\mathbf{g} / \mathbf{c m}^{\mathbf{3}}\right)\end{array}$ & $\begin{array}{c}\text { Módulo } \\
\text { de } \\
\text { finura }\end{array}$ & $\begin{array}{c}\text { Dimensão } \\
\text { máxima } \\
\text { caracterís } \\
\text { tica }(\mathbf{m m})\end{array}$ & $\begin{array}{c}\text { Absorção } \\
\text { de água } \\
(\%)\end{array}$ & $\begin{array}{c}\text { Volume } \\
\text { de } \\
\text { vazios } \\
(\%)\end{array}$ & $\begin{array}{c}\text { Massa } \\
\text { unitária } \\
\left(\mathbf{k g} / \mathbf{m}^{\mathbf{3}}\right)\end{array}$ & $\begin{array}{c}\text { Pulverulento } \\
(\%)\end{array}$ \\
\hline Cimento & 3,01 & - & - & - & - & - & - & - \\
Brita 1 & 2,72 & 3,00 & 6,27 & 12,5 & 3,4 & 48,5 & 1401 & 1,0 \\
Brita reciclada & 2,24 & 2,66 & 6,95 & 25 & 6,9 & 45,9 & 1211 & 0,8 \\
Areia grossa & 2,65 & 2,61 & 1,98 & 1,2 & - & 46,0 & 1411 & 2,0 \\
Areia reciclada & 2,57 & 2,17 & 3,20 & 9,5 & - & 36,1 & 1388 & - \\
\hline
\end{tabular}

Fonte: Autores, 2018.

\subsection{COMPOSIÇÃO DOS TRAÇOS}

Foram confeccionados quatro traços, sendo dois controles e dois com substituição total dos agregados convencionais pelos agregados reciclados, conforme a metodologia de Campitelli (2011) e suas respectivas dosagens são apresentadas na Tabela 2.

Traço $1-\mathrm{fck}=10 \mathrm{MPa}$, traço controle;

Traço $2-\mathrm{fck}=10 \mathrm{MPa}$, traço com RCC;

Traço $3-\mathrm{fck}=20 \mathrm{MPa}$, traço controle;

Traço 4-fck = $20 \mathrm{MPa}$, traço com RCC.

Tabela 2: Dosagem dos traços

\begin{tabular}{lcccc}
\hline & Traço 1 & Traço 2 & Traço 3 & Traço 4 \\
\hline Fck (MPa) & 10 & 10 & 20 & 20 \\
Abatimento (mm) & $80 \pm 20$ & $80 \pm 20$ & $80 \pm 20$ & $80 \pm 20$ \\
Cimento (kg) & 11,8523 & 11,5067 & 16,1482 & 15,6406 \\
Areia (kg) & 34,2885 & 29,2653 & 30,2249 & 25,3794 \\
Brita (kg) & 40,2329 & 40,7720 & 40,4353 & 41,0200 \\
Água (I) & 9,7123 & 11,2121 & 8,9811 & 11,2575 \\
\hline
\end{tabular}

Fonte: Autores, 2018. 
Revista Nacional de

Gerenciamento de Cidades

National Journal of Cities Management

\subsection{PROGRAMA EXPERIMENTAL}

\subsubsection{MOLDAGEM DOS CORPOS DE PROVA}

A moldagem dos corpos de prova cilíndricos $100 \times 200 \mathrm{~mm}$ foi realizada segundo a NBR 5738 (ABNT, 2015). As fôrmas metálicas foram posicionadas sobre uma camada de areia utilizada para nivelar o local e uma camada de óleo foi aplicada às fôrmas para facilitar a desforma dos corpos de prova. A moldagem foi realizada em duas camadas iguais de dos traços de concreto, sendo que cada uma foi adensada com 12 golpes com auxílio de haste metálica (Figura 3).

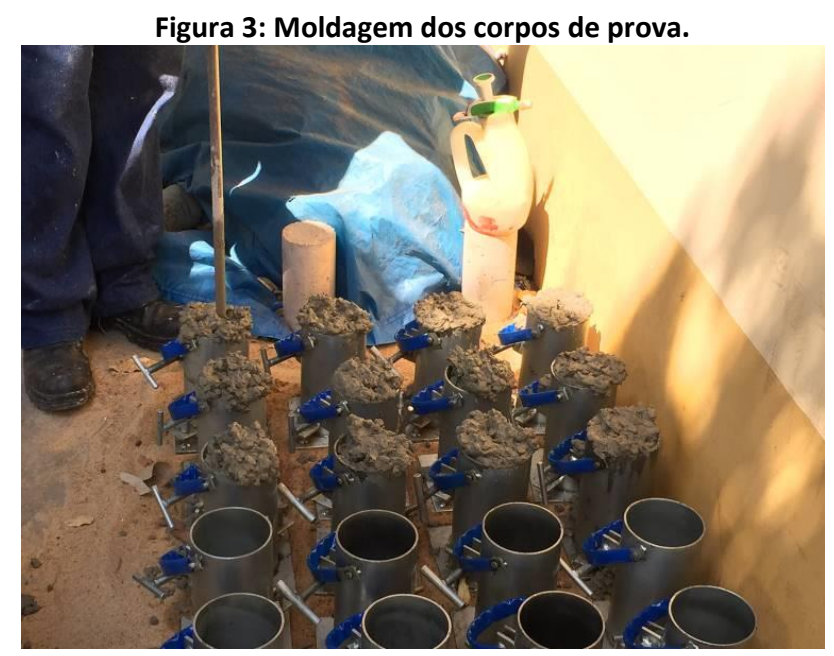

Fonte: Autores, 2018.

O Quadro 2 resume a quantidade de corpos de prova produzidos e idades de ruptura para os traços de concreto estudados.

\begin{tabular}{|c|c|c|c|c|}
\multicolumn{2}{c}{ Quadro 2: Resumo dos ensaios de resistência mecânica } \\
\hline Traço 1 & Traço 2 & Traço 3 & Traço 4 & $\begin{array}{c}\text { Quantidade de } \\
\text { corpos de } \\
\text { prova }\end{array}$ \\
\hline 3 dias-compressão & 3 dias-compressão & 3 dias-compressão & 3 dias-compressão & 2 \\
\hline 7 dias-compressão & 7 dias-compressão & 7 dias-compressão & 7 dias-compressão & 2 \\
\hline 7 dias- tração & 7 dias- tração & 7 dias- tração & 7 dias- tração & 2 \\
\hline 14 dias-compressão & 14 dias-compressão & 14 dias-compressão & 14 dias-compressão & 2 \\
\hline 28 dias-compressão & 28 dias-compressão & 28 dias-compressão & 28 dias-compressão & 2 \\
\hline 28 dias- tração & 28 dias- tração & 28 dias- tração & 28 dias- tração & 2 \\
\hline
\end{tabular}

Fonte: Autores, 2018.

Após 24 horas de cura natural no local de moldagem, os corpos de prova foram desformados, retificados para uniformizar as faces para o ensaio de compressão (Figura 4) e levados à cura em câmara úmida até as idades de ruptura. 


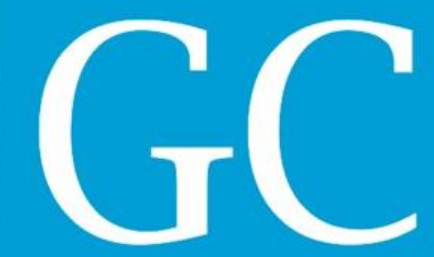

ISSN 2318-8472

Revista Nacional de

Figura 4: Retificação dos corpos de prova.

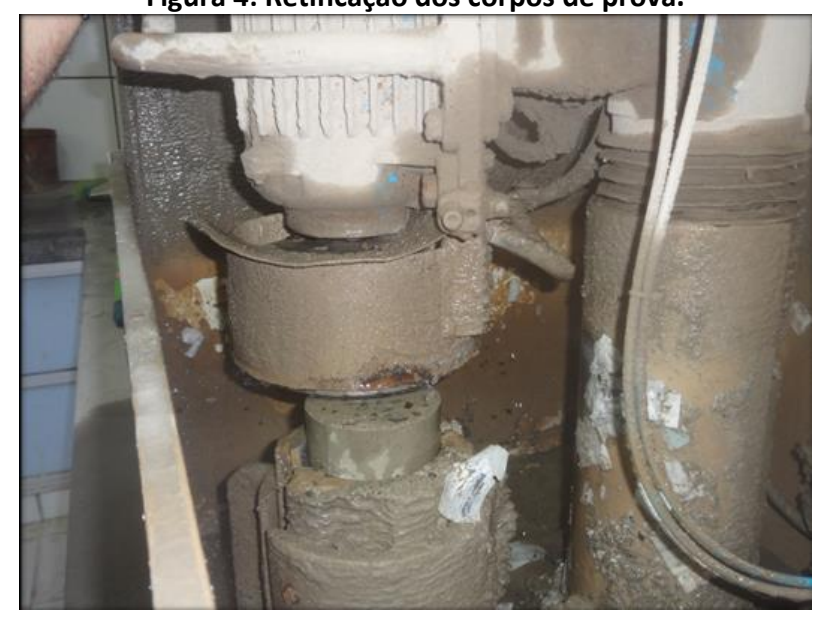

Fonte: Autores, 2018.

\subsubsection{CONSISTÊNCIA PELO ABATIMENTO DO TRONCO DE CONE}

$O$ ensaio de abatimento do tronco de cone é realizado no estado fresco do concreto e mede a consistência e a fluidez, permitindo controlar sua uniformidade. A consistência do concreto é um dos principais fatores que influenciam na trabalhabilidade do material.

Esse ensaio foi realizado segundo as prescrições da NBR NM 67 (ABNT, 1998). Para a realização do ensaio, o tronco de cone foi preenchido em três camada, em que cada uma recebeu 25 golpes com o auxílio de haste metálica. Após o preenchimento e adensamento, a superfície do tronco foi nivelada e o mesmo retirado e posicionado em de maneira invertida ao lado do concreto para a determinação da medida em milímetros do abatimento (Figura 5).

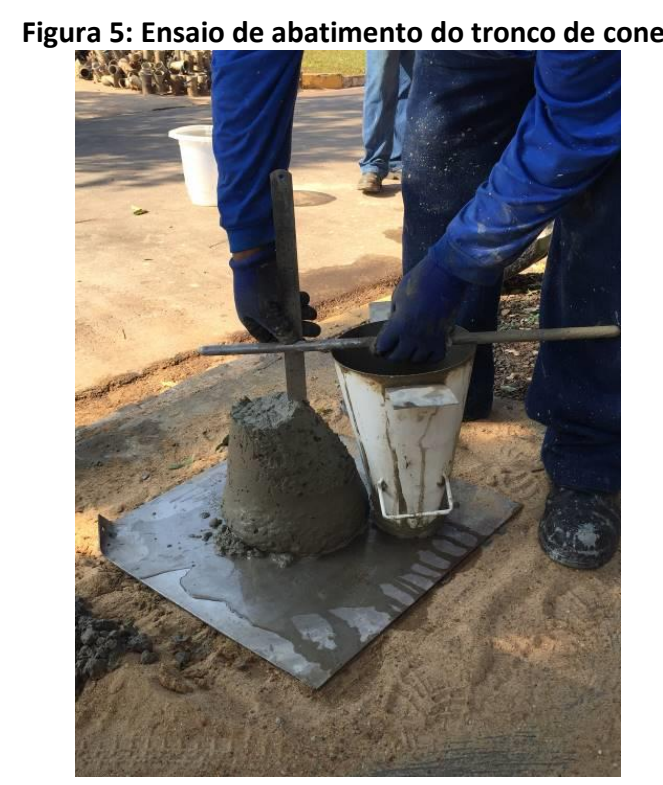

Fonte: Autores, 2018. 
Revista Nacional de

Gerenciamento de Cidades

\subsubsection{RESISTÊNCIA À COMPRESSÃO}

O ensaio de compressão é indicado para se certificar de que o concreto utilizado em obra atingiu a resistência de projeto e foi realizado segundo a NBR 5739 (ABNT, 2007). Ele foi realizado aplicando-se uma força axial, por meio de uma prensa universal, distribuída por todo o corpo de prova, até chegar a ruptura, determinando sua força resistente (Figura 6).

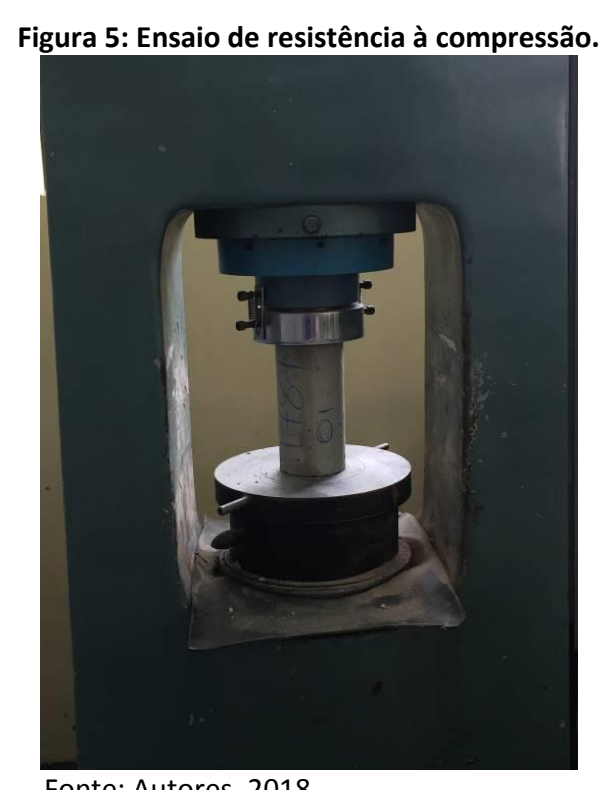

Fonte: Autores, 2018.

\subsubsection{RESISTÊNCIA À TRAÇÃO POR COMPRESSÃO DIAMETRAL}

Este ensaio consiste em determinar a tensão necessária para romper o corpo de prova cilíndrico à tração por compressão diametral, realizado conforme a NBR 7222 (ABNT, 2011). 0 corpo de prova a ser ensaiado foi colocado em posição horizontal na prensa universal e dois placas pequenas de madeiras colocadas entre o corpo de prova e a prensa, como mostrado na Figura 6. 
Revista Nacional de

Figura 6: Ensaio de resistência à tração por compressão diametral.

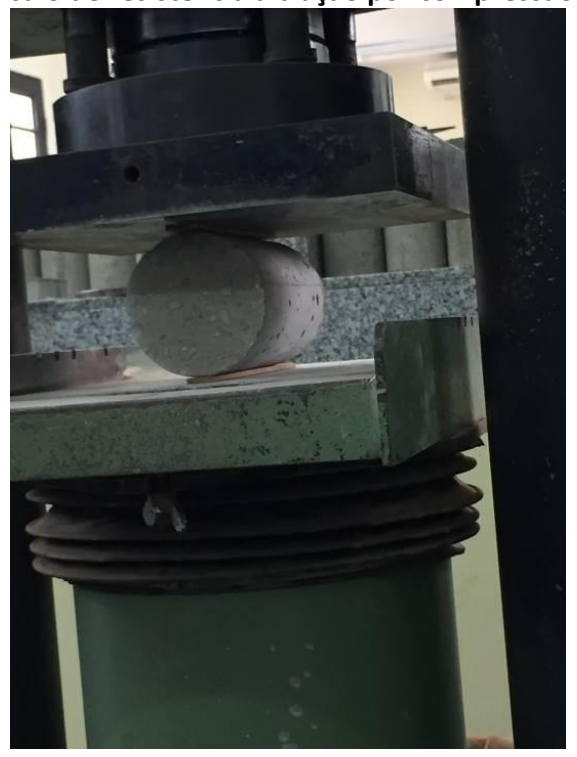

Fonte: Autores, 2018.

\section{RESULTADOS}

Os resultados do ensaio de resistência à compressão e resistência à tração por compressão diametral dos traços de concreto estudados estão apresentados na Figura 7 e na Tabela 3, respectivamente.

Figura 7: Resultados da resistência à compressão.

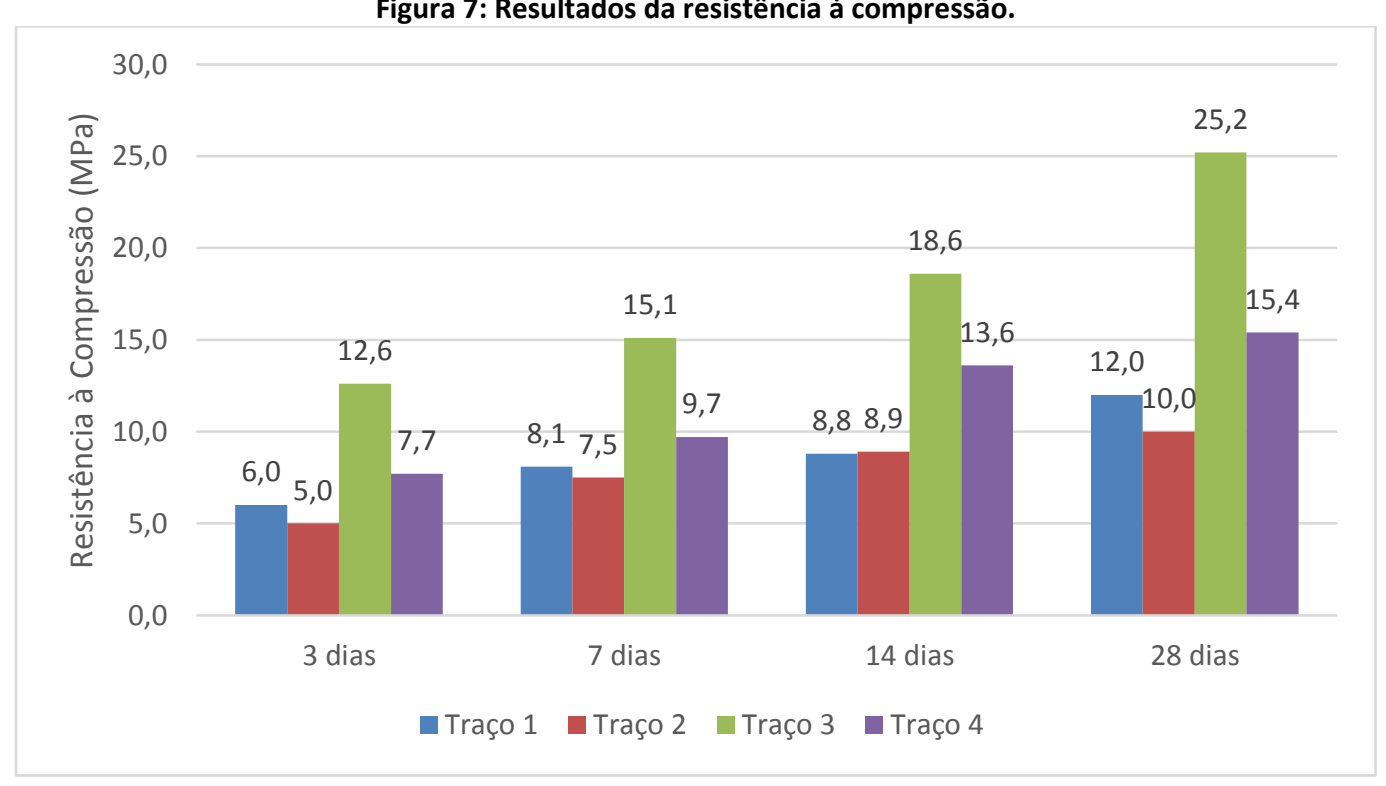

Fonte: Autores, 2018. 


\begin{tabular}{|c|c|c|}
\hline & $\begin{array}{c}\text { Resistência } 7 \text { dias } \\
\text { (MPa) }\end{array}$ & $\begin{array}{c}\text { Resistência } 28 \text { dias } \\
\text { (MPa) }\end{array}$ \\
\hline Traço 1 & 0,70 & 1,40 \\
\hline Traço 2 & 0,90 & 1,50 \\
\hline Traço 3 & 1,80 & 2,40 \\
\hline Traço 4 & 1,40 & 2,00 \\
\hline
\end{tabular}

Fonte: Autores, 2018.

Os resultados demonstram que o uso de agregados reciclados diminui a resistência à compressão quando comparados ao controle, o que se explica pela baixa resistência e maior absorção de água dos agregados reciclados (absorção da brita 1: 3,4 \% e da brita reciclada 6,9 $\%)$.

Aos 28 dias de idade, os traços 1 e 2 obtiveram resultados semelhantes, chegando o traço 1 a resistência de 12,9 MPa e o traço 2 a resistência de 10,2 MPa. O mesmo não ocorreu com os traços 3 e 4, pois houve redução de $39 \%$ da resistência do concreto à compressão com RCC comparado ao controle.

\section{CONCLUSÃO}

Analisando o aspecto visual do agregado reciclado, foi observado a presença de material vermelho dentre o material cinza, o que seria necessário melhorar a qualidade do processo de triagem para excluir o material vermelho. Outra observação foi quanto à dimensão máxima do agregado graúdo da Usina, pois dificultou a moldagem dos corpos de prova, alterando o abatimento, consequentemente interferindo na resistência atingida.

Houve um decréscimo de resistência nos resultados obtidos, por ruptura à compressão, (traço 1 - convencional e traço 2 - RCC - ambos de $10 \mathrm{MPa}$ ) de 12,9 MPa para 10,2 MPa e nos traços 3 (convencional) e 4 (RCC) - ambos de $20 \mathrm{MPa}$, um decréscimo de 20,6 MPa para 15,6 MPa.

Quantos aos ensaios de ruptura à tração por compressão diametral, os traços 1 e 4 não atingiram o valor de $10 \%$ da resistência à compressão (1,29 $\mathrm{MPa}$ e 1,56 $\mathrm{MPa}$, respectivamente), embora apresentaram valores próximos. Já os traços 2 e 3, chegaram aos valores respectivos de 1,02 MPa e 2,06 MPa.

Com base na resistência obtida nos ensaios de ruptura à compressão e à tração por compressão diametral, é possível utilizar este concreto para fins não estruturais como em artefatos de concreto, por exemplo: bancos de concreto, lajotas, pingadeiras de muro, grelhas e meio fio. Podem ser aplicados em praças, estacionamentos, escolas, jardins e pátios.

Logo, o uso desse tipo de material contribui para atenuar os impactos ambientais causados pelo descarte inadequado dos resíduos da construção civil. 
Revista Nacional de

\section{AGRADECIMENTO}

Agradecemos ao Laboratório de Ensaio de Materiais da Unilins pela disponibilidade na realização dos ensaios deste estudo.

\section{REFERÊNCIAS BIBLIOGRÁFICAS}

ASSOCIAÇÃO BRASILEIRA DE NORMAS TÉCNICAS - ABNT. NBR NM 45: Agregado em estado solto - Determinação da massa unitária. Rio de Janeiro. 2006. Janeiro. 2003.

NBR NM 46: Agregados — Determinação do teor de materiais pulverulentos em agregados. Rio de

NBR NM 52: Agregado miúdo - Determinação da massa específica e massa específica aparente. Rio de Janeiro. 2009.

. NBR NM 53: Agregado graúdo - Determinação da massa específica, massa específica aparente e absorção de água. Rio de Janeiro. 2009.

NBR NM 67: Concreto - Determinação da consistência pelo abatimento do tronco de cone. Rio de Janeiro. 1998.

. NBR NM 248: Agregados — Determinação da composição granulométrica. Rio de Janeiro. 2003.

NBR 5738: Concreto - Procedimento para moldagem e cura de corpos de prova. Rio de Janeiro 2015.

. NBR 5739: Concreto - Ensaio de compressão de corpos de prova cilíndricos. Rio de Janeiro. 2007.

NBR 7222: Concreto e argamassa - Determinação da resistência à tração por compressão diametral de corpos de prova cilíndricos. Rio de Janeiro. 2011.

. NBR 16605: Cimento Portland e outros materiais em pó - Determinação da massa específica. Rio de Janeiro. 2017.

ASSOCIAÇÃO BRASILEIRA PARA RECICLAGEM DE RESÍDUOS DA CONSTRUÇÃO CIVIL E DEMOLIÇÃO - ABRECON. História do Entulho. Disponível em: < http://abrecon.org.br/entulho/historia-do-entulho>. Acesso em: 18 mai. 2018.

BRASIL. Conselho Nacional do Meio Ambiente - CONAMA. Resolução $n^{\circ}$ 307, de 05 de julho de 2002. Brasília, DF, 2002. Disponível em: <http://www.mma.gov.br>. Acesso em: 18 mai. 2018.

CAMPITELI, V.C. Fundamentos da dosagem de concretos. Ponta Grossa, PR: UEPG, 2011. 